\title{
O padrão de beleza corporal sobre o corpo feminino mediante o IMC
}

CDD. 20.ed. 152

796.406
Clara Maria Silveira Monteiro de $\operatorname{FREITAS}^{* * * *}$ Ricardo Bezerra Torres LIMA* António Silva COSTA ${ }^{* * * *}$ Ademar LUCENA FILHO
*Universidade de Pernambuco.

** Universidade Federal da Paraíba.

***Faculdade de Desporto, Universidade do Porto - Portugal.

\section{Resumo}

0 objetivo deste estudo foi confirmar a existência de um padrão de beleza sobre o corpo feminino e definilo mediante um parâmetro de caráter científico, qual seja o Índice de Massa Corporal, bem como saber como este corpo é representado socialmente. Participaram 151 sujeitos, entre os quais alunos dos cursos de licenciatura, bacharelado e pós-graduação em Educação Física da Universidade de Pernambuco, respondendo um questionário com perguntas que permitiram a análise de um painel com fotos de sete mulheres entre 18 e 22 anos. 0 estudo confirmou não só a existência de um padrão de beleza sobre o corpo feminino, como também uma tendência à uniformidade na percepção do corpo belo realizada por estudantes e profissionais de Educação Física, bem como por indivíduos que não compõem este subgrupo social.

UnITERMos: Estética; Belo; Imagem corporal; IMC.

\section{Introdução}

Como qualquer tema, a prática do exercício físico pode desencadear inúmeros questionamentos, sendo fonte inesgotável de pesquisa nas mais diversas áreas do conhecimento. Um caminho na ciência pode se desdobrar em várias outras trilhas a serem percorridas pelos pesquisadores. Este estudo inicia sua caminhada pela questão relativa a um motivo frequentemente indicado por indivíduos praticantes de exercícios físicos, que é a busca por um corpo adequado ao padrão de beleza corporal vigente. Nesse cenário, "o corpo, e o conjunto das representaçôes e práticas sobre ele, tornou-se objeto de reflexão, de conhecimento e de intervenção" (SOARES, 1997, p.106). Discutir este tema é refletir, conhecer e fornecer subsídios para uma melhor compreensão do fenômeno. A isto se propôs este estudo, de forma a produzir conhecimento multidisciplinar e atual, integrando a Educação Física com as Ciências Sociais. Mais que isso, ele quis, como ensina ARonowitz (2000) citado por Demo (2000), debruçar-se sobre as áreas das "humanidades", usualmente marginalizadas, combatendo a propensão para a produção exclusiva do conhecimento de utilidade mercadológica, para insurgir-se contra uma universidade submissa ao mercado, glorificando sua missão-mor de educar com olhos para o pensamento crítico inserido na multiculturalidade.

Esse estudo teve como objetivo geral: averiguar a existência de um padrão de beleza corporal e defini-lo mediante o IMC. Outros objetivos específicos foram averiguar a existência de um padrão de beleza corporal vigente; definir o padrão de beleza corporal vigente mediante o IMC e comparar o padrão de beleza corporal vigente entre os estudantes e profissionais da área de Educação Física e demais indivíduos fora deste grupo.

A problematização inicial partiu da seguinte questão: Por que alguém se exercita? Estudos mostram que são altas as porcentagens de resposta em que a estética é apontada como justificativa principal por praticantes de exercícios físicos (Almeida, Santos, Pasian \& Loureiro, 2005; Cohen-Mansfield, Marx, Biddison \& Guralnik, 2004; Damasceno, 2005; Freitas \& Santiago, 2005; GarCia \& Lemos, 2003). SÁ (1992) citado por ANZAI (2000) verificou que este era o motivo para a prática de $70 \%$ dos frequentadores de academia de ginástica. Em outras investigações sobre o tema, 
os números divergem, mas seguem em altos níveis. Nigro (1992) citado por ANZAI (2000) diz que este índice chega a 83,2\%; DANTAS (1988) citado por ANZAI (2000) afirma atingir 85\%.

Além de evidenciar o poder que as motivações estéticas exercem sobre os indivíduos fisicamente ativos, tais resultados atestam a vasta abrangência do fenômeno, já que os estudos foram realizados em diferentes cidades brasileiras. É possível até verificar a repetição do fato para além das fronteiras territoriais e, porque não dizer, sócio-culturais do nosso país. Em Portugal, 67\% das mulheres com idade entre 40 e 51 anos identifica a estética como o motivo principal para a prática de aeróbica (AFONSO, Fernandes, Gomes, SOARes \& FonseCA, 2000). Está claro que um elevado número de pessoas pelo Brasil e pelo mundo afora pratica exercício físico em busca de um corpo belo. Dessa verdade, surgem dúvidas: o que essas pessoas definem como um corpo belo? Elas seguem os mesmos critérios para perceber um corpo como belo, fazendo existir um padrão de beleza corporal? Os poucos estudos no campo da Educação Física voltados para esta temática apontam para a existência de um padrão de beleza corporal vigente na sociedade brasileira (ANDRAde, 2003; ANZAI, 2000; Belloni, 2000; Damasceno, 2005; Ferreira \& Feijó, 1999; Garcia \& Lemos, 2003; Kateshita \& Almeida, 2006; KNijnik \& SimŌes, 2000; Lacerda, 1998; Mata, 1998; Novaes, 1999; Soares, 1997; UvinHA, 1996). Entretanto, apesar dos estudiosos da estética, da cultura (e) do corpo se aproximarem da unanimidade quanto à existência do referido padrão, abordando-o em seus trabalhos sob diferentes olhares, nenhum deles traz qualquer descrição do mesmo.

Há, de fato, esboços de uma resposta para suprir esta lacuna. Para ANZAI (2000, p.73), “O padrão atual de beleza física ocidental, proposto pela publicidade e pela mídia, é o da figura longilínea, tipo físico das modelos Claudia Schiffer, Cindy Crawford e Naomi Campbell, ou o das estrelas de cinema como Sharon Stone, Julia Roberts ou Demi Moore (...)". Tal afirmação é feliz ao mencionar a influência da mídia como contribuinte importante na definição do referido padrão e sugerir a magreza peculiar das modelos de atrizes como tal. Porém, numa análise mais acurada, a inexatidão ainda permanece. Seria o corpo longilíneo das modelos o padrão brasileiro se em nossa sociedade a altura média das mulheres no Brasil é de 1,60 m? (IBGE, 2003). Qual é exatamente o padrão de beleza: a pele clara e os cabelos negros de Moore e Crawford; a pele alva e os olhos claros das loiras Stone e Schiffer; ou o conjunto negro de Campbell? E, diante das diversas características genotípicas, qual delas utilizar na definição do referido padrão?

Antes de responder tais questões, convém ressaltar que a insinuação acima, como se pode ver pelos exemplos citados, limita-se a dar um parecer acerca do padrão de beleza que recai sobre a mulher. É útil para este trabalho porque é o corpo feminino que é abordado neste trabalho. E isto é feito, não por qualquer preconceito ou motivado por desejos particulares. $\mathrm{Na}$ verdade, seu objetivo vislumbrava ocupar-se de corpos de ambos os gêneros, para que homens e mulheres pudessem, de acordo com a metodologia explicada mais adiante, analisar a si e ao outro, o que permitiria uma abordagem mais completa. Infelizmente isso não foi possível, restando apenas o olhar sobre os corpos femininos, conforme está explicado adiante. Retomando a opção pelas características genotípicas para definição do padrão, ressalta-se que, aqui, nenhuma delas será utilizada. Ao buscar o exercício físico como ferramenta de intervenção estética, os indivíduos almejam promover mudanças em seus corpos. Porém, todos estão cientes de que essa prática não efetuará alteraçōes em tais características genotípicas como cor da pele, dos olhos e dos cabelos. Os fins estéticos pretendidos estão ligados à silhueta, à forma que os corpos podem assumir para serem classificados como belo.

\section{Conceituando beleza}

ECO (2004, p.193) já se perguntou: "Que cânones, gostos e costumes sociais permitem considerar 'belo' um corpo?" A tentativa de encontrar uma definição universal para este vocábulo pode resultar em um interminável jogo de palavras que se limita a expressam valores. E valor é algo individualíssimo. Apesar disso, convém o esforço iniciando-se pelo passo mais simples e talvez o mais eficiente. Para Ferreira (2000), em léxico que carrega o seu prenome Aurélio como título e pelo qual é mais conhecido, beleza, entre outras definições, é a qualidade de algo que é agradável aos sentidos. Apesar da simplicidade, é uma definição adequada e abrangente. Com ela, evita-se a tendência de se definir algo, especialmente os substantivos abstratos, por meio da apresentação de exemplos, normalmente pela citação de fato, pessoa ou coisa que se enxergue como detentora da qualidade do algo a ser definido. Definir o belo citando algo ou alguém que se acha belo, mesmo que seja fato, coisa ou pessoa considerada bela em diferentes culturas, não é defini-lo, mas exemplificá-lo.

Estudos enfatizam que quase todas as culturas têm padrões específicos relativos ao que é atrativo 
ou desejável (AfONSO et al., 2000; BARROS, 2005; Borges, 2005; Castro, Andrade \& Muller, 2006; Costa, 2002; Freitas \& Santiago, 2007; Furlan \& Bocchi, 2003; Goldemberg, 2005a; TeIXeIra, 2001). A beleza pode, então, se expressar de forma idêntica em muitas delas. Em contrapartida, o que é belo para um povo pode não receber a mesma qualificação em outra sociedade. Entretanto, em conformidade com a sucinta definição já vista, em qualquer uma delas, aquilo que é visto como belo será, sem dúvida, algo que causa satisfação, prazer, satisfação, agrado ao observador. Este pensamento, vale dizer, é a base da Teoria Kantiana da Beleza.

Sendo uma das grandes contribuiçõos que apareceram no campo da Estética, o pensamento kantiano chegou como uma reação que objetivou deslocar o centro da existência da Beleza do objeto para o sujeito, operando o que Geiger, em Suassuna (2005), chama de "uma verdadeira destruição da Estética". Este fenômeno se deu porque, em vez de buscar a saída para os problemas estéticos, Kant procurou mostrar que para eles não haveria solução, explicando que esta impossibilidade decorreria da diferença extrema existente entre os juízos de conhecimento e os juízos estéticos (ou juízos de gosto).

Enquanto os juízos de conhecimento baseiam-se em propriedades do objeto e, por isso, emitem conceitos de validez geral, os juízos estéticos não emitem conceitos, resultando de uma mera reação pessoal do contemplador frente ao objeto, e não diante de propriedades deste. Ao serem comparados entre si, tais juízos mostram-se diferentes. Porém, conforme será visto adiante, há semelhança entre eles, o que se configurará no primeiro paradoxo kantiano sobre a beleza.

Ao se proferir um juízo estético como "Este corpo é belo", não se emite nenhum conceito universal oferecido pelas propriedades do objeto (corpo), mas somente uma sensação que foi agradável ao sujeito. Ao mesmo tempo, quando diz "Este corpo é belo", o sujeito não se contenta com o fato de isto ter validade só para ele: demanda um consentimento geral, como se tivesse emitido um conceito objetivo. Assim, Kant, em Suassuna (2005), afirma que a Beleza, ou melhor, "a satisfação determinada pelo juizo de gosto" - que é como ele preferia chamar a Beleza - é, em primeiro lugar e antes de mais nada, "aquilo que agrada universalmente sem conceito".

O "universal sem conceito", como ficou mais conhecido, acaba provocando uma questão: por que o juízo estético, essencialmente subjetivo, exige paradoxalmente o assentimento mais geral possível, a validez universal? Quem responde é o próprio Kant, explicando que "a satisfação determinada pelo juízo de gosto, é resultante de faculdades necessariamente comuns a todo homem, a sensibilidade, ou imaginação, aliada talvez ao entendimento". Assim, tendo os homens essas faculdades, cujo jogo, sem conceitos e livre, causa a sensação de prazer ou desprazer, é natural que o sujeito, ao experimentar uma sensação de prazer diante de um quadro, romance ou de um corpo, requeira o consentimento de todos os homens, a aprovação geral.

Foi por isto que esta investigação buscou compreender a beleza como uma necessidade subjetiva que parece, ao homem, objetiva. Com o uso de imagens apresentadas no instrumento utilizado na pesquisa, procurou-se saber qual juízo estético elas provocariam, bem como se poderia ser classificado como universal o juízo estético referente à beleza.

Em sintonia com esse quadro, Simmel (1988) trata a beleza como uma qualidade do ser humano, uma relação entre as partes e a imagem. Cabe referir que encontramos também em KaNT (1990, p.32) uma fonte conceitual preciosa, que define o belo como algo que encanta, trazendo ao semblante do ser humano a viva sensação declarada por um olhar de "esplendorosa serenidade, por arroubos do sorriso e, muitas vezes, por um claro regozijo".

Nesse contexto, o corpo belo seria, então, aquele cujas formas provocassem tais sensaçôes e seria possível afirmar que existe um padrão de beleza corporal na medida em que certas formas corporais fossem de igual maneira agradáveis aos sentidos de diversos indivíduos, estejam eles inseridos em uma mesma cultura ou não.

\section{A existência de um padrão sobre a beleza}

Ao analisar a beleza corporal, é possível afirmar que, sobre ela, recai um "padrão" (SOARES, 1997, p.104). As menções ou alusões a este padrão se apresentam em múltiplas maneiras: "a imagem consensual do belo" (LACERDA, 1998, p.80); "cultura estética do corpo do brasileiro" (NOVAES, 1999, p.42); "ditadura do corpo" (Ferreira \& Fejjó, 1999, p.122); "padrão de corpo" (ANDRADE, 2003, p.130); "uma estética corporal padronizada" (MATA, 1998, p.36); "imagem (...) ideal” (GARCiA \& LEMOS, 2003, p.34); "padrão atual de beleza física ocidental” (ANZAI, 2000, p.73). E o fenômeno ultrapassa fronteiras. Do Reino Unido, vem a referência a "uma aceitável superfície corporal exterior" (MAGUIRE $\&$ Mansfield, 1998, p.122); de estudos em Colônia (Alemanha), Praga (República Tcheca) e Moscou (Rússia), comentários sobre os "nossos ideais de beleza” (Mrazek, Fialová \& Bykhovskaya, 1998, p.52). 
Quando se fala em padrão, tem-se a ideia de uniformidade. No "campo" da Educação Física e do esporte, padrão e uniforme chegam a ser sinônimos quando usadas para se referirem à vestimenta de uma equipe desportiva, tendo que ser igual para todos. Relacionada à beleza, que é um conceito bastante subjetivo, o padrão de beleza corporal seria um conjunto de características que um corpo deveria apresentar para ser considerado como belo por um determinado grupo de indivíduos. Porém, esta não é a única idéia associada à palavra padrão.

FERREIRA (2000) traz outras definiçôes para padrão: "1. Modelo oficial de pesos e medidas; 2 . O que serve de base ou norma para avaliação, medida; 3. Objeto que serve de modelo à feitura de outro". Ligando estes conceitos à beleza corporal, especialmente o segundo e o terceiro, a ideia de padrão passa a ser viável. Tomando a segunda definição, o padrão de beleza corporal passaria, então, a se consubstanciar em um corpo que servisse de base para avaliação, ou seja, que fosse o parâmetro ao qual, com o objetivo de ser qualificado como belo, um segundo corpo fosse comparado. Quanto à definição de número três, mais estreitamente conectada com o exercício físico, o padrão se concretizaria em um corpo que forneceria as formas a serem copiadas na construção de outro corpo que buscasse ser belo.

\section{Os critérios para definição do padrão}

ANZAI (2000) elenca alguns ícones femininos do mundo das passarelas e do cinema como encarnações do padrão de beleza física. Quem puder visualizar as atrizes e modelos citadas poderá também observar a variedade genotípica que a espécie humana pode apresentar. Apesar de peles, olhos e cabelos de diferentes cores e tonalidades comporem o substantivo corpo, o conceito que será utilizado para este estudo será o de corpo-lugar: ele é concebido como uma porção de espaço com as suas fronteiras, os seus centros vitais, as suas defesas e fraquezas, a sua couraça e os seus defeitos (SiLVA, 1999). Conforme este entendimento, o que merece destaque para a Educação Física é este lugar do corpo, o seu espaço. E para estabelecer critérios em relação ao espaço e sua relação com a estética é necessário, antes de tudo, medi-lo.

Para medir lugares, nada melhor que altura, largura, comprimento e circunferência, por exemplo. O corpo-lugar não foge à regra; sobre ele tais medidas também serão utilizadas. Relacionadas entre si, elas determinam os limites do corpo, o lugar que ele ocupa, o que acaba por determinar a forma do lugar, a forma do corpo, bem como compõem o sistema de medida escolhido para servir de base para descrição do padrão de beleza corporal já mencionado: o Índice de Massa Corporal - IMC. Também conhecido como Índice de Quetelet, ele é calculado pela divisão do peso do indivíduo (em quilogramas) pelo quadrado da sua estatura (em metros). Além de servir para avaliar riscos à saúde, já que a propensão a problemas relacionados à obesidade aumenta para a maioria das pessoas com um IMC superior a 25 (ACSM, 2003), por meio dele é possível classificar o indivíduo de acordo com sua massa corpórea, bastando verificar em que determinada faixa de valores o resultado da fórmula acima se enquadra.

Sobre esta classificação, é sabido que ela não é uniforme no que tange a valores e nomenclatura, dadas as diversas formas em que as tabelas são apresentadas pela literatura especializada e pelos órgãos de estudo da população e saúde, o que dificulta a determinação de qual delas deveria é a mais adequada e deveria ser mais aceita.

Para servir de base a uma nomenclatura associada ao padrão de beleza corporal foi escolhido o Índice de Massa Corporal (IMC). Sobre esta classificação, é sabido que ela não é uniforme no que toca a valores e nomenclatura, dadas as diversas formas em que os indicadores são apresentados pela literatura especializada e pelos órgãos de estudo da população e saúde, o que dificulta a determinação de qual delas deveria ser a mais adequada e mais aceita. Como parâmetro, optou-se pela Tabela de Índice de Massa Corporal utilizado pela World Health Organization - WHO (2008), pelas razões que seguem.

Primeiramente, é utilizada por um órgão de referência mundial; é quase idêntica à tabela usada pelo Instituto Brasileiro de Geografia e Estatística, que a ela faz menção (IBGE, 2002), sugerindo que os dados do órgão internacional serviram como fundamento para a construção daquela usada pelo órgão brasileiro. Em segundo lugar, seu ponto de divergência com o órgão de estudo nacional encontra fundamento na tabela publicada pelo Colégio Americano de Medicina do Esporte - ACSM - outro nome de respeito e referência no ramo da Educação Física. Outra razão decorre do fato de que o IMC é um índice decorrente de um processo de medição simples. E por último, porém como razão mais importante, é o índice que classifica os indivíduos como magro, normal e obeso. E em consonância com ANZAI (2000), que menciona os ícones da moda e do cinema, é na magreza que parece residir o padrão e o ideal de beleza (Wolf, 1992). Comprovam isto $65 \%$ dos que praticam exercícios físicos por motivos estéticos, que o fazem com o objetivo específico de emagrecimento (DANTAS, 1988 citado por ANZAI, 2000). 


\section{A fusão entre a beleza e o corpo magro}

Conforme se pode verificar nas pinturas da época, os períodos anteriores ao século XIX traziam um padrão que retratava corpos volumosos e rotundos. Nessa época "a gordura foi sinônimo de saúde, beleza e sedução” (ANDRADE, 2003, p.126). O excesso de peso era típico dos abastados e nobres, da classe dominante, já que o viver deles era abastecido do melhor alimento da época e se afastava de qualquer atividade física desgastante. Para a plebe, restava o trabalho braçal extenuante e a limitação na disponibilidade de comida. Ser obeso ou estar acima do peso estava associado ao poder, financeiro ou político. Esta forma de se pensar a estética corporal chega a 1830, quando é inventado o código da beleza (BARROS, 2005; Castro, Andrade \& Muller, 2006; Maués, 2003; Pontes, 2006; Teixeira, 2001; Wolf, 1992).

É nas primeiras décadas do século XIX que reside o marco temporal da mudança na visão estética sobre o corpo, fechando os olhos para a obesidade e mirando em direção à magreza:

$\mathrm{Na}$ década de 1840 , foram tiradas as primeiras fotografias de prostitutas nuas. Anúncios com imagens de 'belas' mulheres apareceram pela primeira vez em meados do século. Reproduções de obras de arte clássicas, cartōes-postais com beldades de sociedade e amantes dos reis, gravuras de Currier e Ives e bibelôs de porcelana invadiram a esfera isolada à qual estavam confinadas as mulheres da classe média (Wolf, 1992, p.18).

E não tardaria para que o Brasil apresentasse reflexos dos episódios narrados. Junto com as novas tecnologias de reprodução de imagens, chegaram, obviamente, novas imagens. Estas traziam corpos sob uma nova forma, mais delgados, frutos de uma também nova sociedade que já se desenvolvia: a industrial. Produzidas em escala característica da sociedade vigente, perpassando todas as classes sociais, as imagens fazem do corpo um fenômeno de moda. Não como algo ligado à indústria de vestuário, mas, como explica Tarde a moda como um sinônimo de culto e ao que é novo e de imitação de modelos nacionais ou alienígenas. "As pessoas preferem assemelhar-se aos inovadores contemporâneos e menos aos seus antepassados" (LIPOVETSKY, 1989, p.44).

Destarte, há uma relação entre a obesidade e o padrão de beleza corporal; uma relação de negação. Simbolizando o velho, o passado, aquela cede seu lugar à magreza, que é a novidade e, portanto, preferida; sua influência é no sentido de significar o indesejado pela sociedade, o que as pessoas devem evitar. Este aspecto acentua-se quando, já no século
$\mathrm{XX}$, as pesquisas científicas passam a decretar a obesidade como antítese de saúde, culminando na sua rotulação oficial, pela Organização Mundial da Saúde, como doença. Assim, ela passa a ser enxergada "como um sinal tangível de falta de controle, impulsividade, auto-indulgência, enquanto que corpo magro é um testemunho do poder da autodisciplina, um exemplo de domínio da mente sobre o corpo e de um virtuoso sacrifício" (ANDRADE, 2003).

\section{Beleza corporal e moda}

Vulgarmente, a palavra moda é associada a roupas, vestimentas e afins. Embora válida, não é esta a acepção que interessa a este estudo. Conforme explicam alguns estudiosos (BARROS, 2005; LIPOVETSKY, 1989; Maués, 2003; TeIXeIra, 2001), moda engloba os mais diversos aspectos de uma cultura, como os objetos de decoração, a língua, o agir, as obras culturais e seus autores, as ideias e os gostos, contagiando-os com seus entusiasmos e suas oscilações velozes.

Forma específica da mudança social, a moda não está ligada a um objeto determinado, é antes de mais nada um dispositivo social caracterizado por uma temporalidade especialmente breve, por transformações mais ou menos fantasiosas e que podem, por esse motivo, afetar esferas muito diversas da vida coletiva (LIPOVETSKY, 1989). Para BAUdRILLARD (2005), a sociedade de consumo criada pela diversidade dos objetos, dos serviços, dos bens materiais, gerando como que uma categoria de mutação fundamental na ecologia da espécie humana, está ligada à efemeridade, ao descarte frequente dos objetos de consumo. Esse fato acarreta uma renovação sazonal, antes mesmo que ocorra um desgaste utilitário do produto. Nesse sentido estudos realizados por NaTANSOHN (2005), Goldemberg (2005b), Botti (2003) e BÉrGAMO (2004) trataram da aparência enquanto causa e efeito de um sistema comunicacional. Assim, a moda é vista como um fenômeno multiforme e não se reduz apenas a prática vestimentárias. Ela faz referência a um tempo social. Como retrata SIMMEL (1988), "a mudança freqüente da moda representa também uma sujeição considerável do indivíduo”.

E quando analisada e definida no nível dos indivíduos, mais fundamentalmente, é devido ao desejo destes de se assemelharem aos que são considerados superiores, àqueles que resplandecem pelo prestígio e pela classe, que os decretos da moda conseguem difundir-se (LIPOVETSKY, 1989). 


\section{Beleza corporal e esporte}

A competição entre os seres humanos remonta aos primórdios da humanidade, constituindo um "concomitante natural e sadio da vida do homem" (KLAFS \& LYON, 1981, p.3). O mesmo, todavia, não pode ser dito do esporte, apesar de não podermos classificá-lo, em contrapartida, como um fenômeno recente. A prática desportiva de alto rendimento também sofre influência da moda. Aliás, tão perfeita combinação não poderia haver entre ela, o esporte e a sociedade, posto que, "mais fundamentalmente, é devido ao desejo dos indivíduos de se assemelharem aos que são considerados superiores, àqueles que resplandecem pelo prestígio e pela classe, que os decretos da moda conseguem difundir-se" (LiPOVETSKY, 1989, p.53). Tal difusão ocorrerá de forma mais acentuada e notória quanto da inserção da mulher naquela prática. Como um fato novo, ela reveste-se de todos os atrativos que a moda lhe impõe. Apesar de toda discriminação inicial, reflexo de um evento transgressor da ordem social, a mulher no esporte passou a ensejar o culto e a emulação, especialmente à mulher vencedora.

Vencer, no esporte ou fora dele, resulta em sucesso, prestígio, reconhecimento. Na pluralidade das modalidades, principalmente as clássicas provas do atletismo, vencer também exige certos requisitos, ora combinados, ora isolados, como força, agilidade, velocidade, etc., o que se reflete em corpos fisicamente preparados. Ao buscar semelhança com tais corpos, o que se deseja não é a capacidade de obter os resultados relacionados à modalidade, mas o poder de simbolizar superioridade, auferindo semelhante prestígio ao indivíduo.

O domínio, a consciência de seu próprio corpo só puderam ser adquiridos pelo efeito do investimento do corpo pelo poder: a ginástica, os exercícios, o desenvolvimento muscular, a nudez, a exaltação do belo corpo... tudo isso conduz ao desejo de seu próprio corpo através de um trabalho insistente, obstinado, meticuloso, que o poder exerceu sobre o corpo das crianças, dos soldados, sobre o corpo sadio (Foucault, 1979, p.146).

Da exclusão na Grécia antiga, defendida pelo Barão de Coubertin na retomada dos Jogos Olímpicos da Era Moderna em 1896, até a cada vez maior participação em Olimpíadas, a mulher faz do esporte um campo de luta pela emancipação feminina. Mas com o esporte, o corpo passa a ter um papel dominante. E as atletas, juntamente com sua imagem corporal, são moldadas pelo "mito do belo", traduzido no "discurso da beleza do corpo feminino", "um discurso pronto para construir um corpo feminino num tamanho específico, com gestos e movimentos restritos, diferentes e sedutores" (KNIJNIK \& SiMŌES, 2000, p.199). E é esse tamanho específico de corpo-atleta que passa a seduzir, a penetrar no imaginário social, sendo admirado, por vezes idolatrado e, consequentemente, imitado, comprovando o esporte com um elemento ditador de normas sobre o corpo e o desejo femininos. "Essencial enquanto veículo do ser (atleta) no mundo, o corpo também é estampa viva dos estereótipos de beleza e feiúra” (KNIJNIK \& SIMŌEs, 2000, p.198).

\section{Beleza corporal e mídia}

Desde a Grécia antiga até os dias atuais, sempre existiu o interesse pelas coisas e pessoas belas (ECO, 2004). Com a criação e desenvolvimento de instrumentos de captação e divulgação de imagem, seja ela estática ou em movimento, o corpo passa a ser mostrado e visto em escala mundial. Hoje, mais do que nunca, com o advento aprimoramento de um dos mais revolucionários meios de comunicação, informação e entretenimento de massa, a internet, imagens corporais atingem mais e mais pessoas, contribuindo para uma padronização do belo que já estava consolidada graças a outros meios de comunicação mais antigos, mas não menos eficientes. Um desses meios vem acompanhando a concomitante evolução das mulheres e do mito da beleza. De acordo com Wolf (1992), as revistas femininas foram responsáveis pela democratização da beleza, especialmente quando começaram a publicar anúncios na virada do século XIX para o XX. Mais do que refletir a evolução da história, parte de sua função foi determiná-la. Por mais de 100 anos elas colaboram para a alteração do papel da mulher nas sociedades onde estão inseridas, servindo aos interesses do sistema econômico, dos anunciantes e do governo, esferas predominantemente masculinas.

Tais interesses, notadamente os de mercado, passam a utilizar, como já foi dito, as imagens de beleza, principalmente na criação de dilemas existenciais femininos relacionados à aparência, um deles ligado ao fenômeno da obesidade já abordado. A mesma autora traz números da sociedade americana que ilustram este fato. Artigos relacionados a dieta aumentaram em 70\% de 1968 a 1972. Na imprensa popular, esse tipo de artigo progrediria geometricamente de forma surpreendente, partindo de um total de 60 durante o ano de 1979 para 66 durante o único mês de janeiro do ano seguinte. Quanto à publicidade, a renda proveniente de anúncios de cosméticos/artigos de toalete gerou para as revistas, 
em 1989, um lucro de 650 milhões de dólares, enquanto sabōes, produtos de limpeza e de polimento chegaram a somente um décimo deste valor. Assim, a aparência física passa a ter outra conotação na sociedade ocidental nessa época, que ECO (2004) chama de Beleza do Consumo, em que os ideais de beleza são determinados pelo interesse econômico.

Com o advento de novos meios de comunicação, crescem paralelamente a força do mercado e da manipulação masculina das imagens de beleza. "Em 1988, o espectador médio nos Estados Unidos viu 14\% mais propaganda na TV do que dois anos antes, ou 650 anúncios por semana de um total de 1000 anúncios por dia” (ECO, 2004, p.103). Alavancadas pela cultura de massa, as indústrias chegam a cifras astronômicas - 33 bilhōes de dólares por ano para a indústria das dietas; 20 bilhões por ano para a dos cosméticos; cirurgia plástica estética, com 300 milhões de dólares; pornografia, o maior setor da mídia, com sete bilhões de dólares anuais. $\mathrm{O}$ mito da beleza se torna um fenômeno quase universal, invadindo as mais diversas culturas, ampliando o mercado para tais indústrias. "Enquanto o horário nobre da televisão e a imprensa em geral dirigida às mulheres forem sustentados pelos anunciantes de produtos de beleza, o enredo de como as mulheres aparece na cultura de massa será ditado pelo mito da beleza" (Eco, 2004, p.370). E hoje, quando muitas pessoas passam mais tempo "on line"

\section{Métodos}

Esse estudo analisou a imagem do corpo feminino à luz da pesquisa quali-quantitativa, de formato descritivo (Thomas \& Nelson, 2002). Seus dados foram categorizados, tabulados e apresentados à luz da estatística descritiva, acompanhados de uma leitura analítica das variáveis mais significativas.

Os sujeitos objeto da investigação foram alunos do curso de Bacharelado, Licenciatura e Pósgraduação em Educação Física, da Escola Superior de Educação Física da Universidade de Pernambuco em Recife - PE e alunos do Curso de Especialização em Educação da Faculdade de Formação de Professores de Nazaré da Mata da UPE, realizado na cidade de Barreiros, em Pernambuco. A escolha destes sujeitos buscou alcançar principalmente um dos objetivos específicos, que foi comparar o padrão de beleza corporal vigente entre os estudantes e profissionais da área de Educação Física e demais indivíduos fora deste grupo. do que "on life", numa sociedade onde imagens viajam o mundo tão rapidamente quanto um clique de botão, esses números, esse fenômeno e esse efeito sobre o corpo feminino estão seguramente multiplicados.

E não seria o Brasil a ficar imune à globalização do mito da beleza. Prova disso são as informações trazidas por VANNUCHI (2004), oriundas de uma pesquisa internacional encomendada por uma famosa marca de sabonete e coordenada por psicólogas da Universidade de Harvard e da London School of Economics. As brasileiras, responsáveis por posicionar o país entre os 10 maiores mercados de cosméticos do mundo, perdem apenas para as japonesas no quesito insatisfação com a aparência física. Delas, $54 \%$ já cogitaram a hipótese de cirurgia plástica e $7 \%$ já se submeteram a tal procedimento, o que configura o maior número entre os países pesquisados.

Todos estes dados só vêm a confirmar o fato contra o qual ADORNo e HorkHEIMER citados por LipOVETSKY (1989) se insurgiam já na última década de 40: a manipulação e padronização das consciências, obra da "monstruosa" fusão da cultura da publicidade e do divertimento industrializado. De produtos de beleza a brinquedos e filmes pornográficos, assiste-se, como brilhantemente resume FoUCAULT (1979, p.147), a "um novo investimento que não tem mais a forma de controle-repressão, mas de controle-estimulação: 'Fique nu... mas seja magro, bonito, bronzeado".

\section{Amostra}

Foi definida a população, dentro do critério de representatividade numérica que possibilitasse a generalização dos conceitos teóricos que se validaram na abordagem quali-quantitativa. A preocupação passou pelo aprofundamento e abrangência da compreensão do fenômeno.

Em face desse quadro, recorreu-se a MinaYo (2006) e a Demo (2000), que apresentam a amostragem nos seguintes aspectos: a) privilegia os sujeitos sociais que detêm os atributos que o pesquisador pretende conhecer; b) considera em número suficiente para permitir certa reincidência das informações, porém não despreza informações ímpares cujo potencial explicativo tem que ser levado em conta; c) entende que, na sua homogeneidade fundamental relativa aos atributos, o conjunto dos entrevistados possa ser diversificado, para possibilitar a apreensão 
de semelhanças e diferenças; d) esforça-se para que a escolha do "locus" e do grupo de observação e informação contenham o conjunto das experiências e expressōes que se pretende objetivar com a pesquisa.

Foram entrevistados 151 sujeitos maiores de 18 anos, de ambos os sexos (108 mulheres e 43 homens).

\section{Instrumentos}

Existe uma falta de informações e pesquisas acerca da imagem corporal e isto se deve provavelmente ao caráter multidimensional e multifacetado da imagem corporal, definida como um fenômeno psicossocial, físico e fisiológico, o que torna difícil sua mensuração e avaliação (KNIJNIK \& SimŌES, 2000). Esta dificuldade se estende, por consequência, para a escolha ou desenvolvimento da técnica a ser escolhida para recolha de dados. Entretanto algumas alternativas já foram desenvolvidas tais como: reunião de partes do corpo, testes de imitação corporal, identificação de partes do corpo, desenho da figura humana, questionários com escalas, entre outras. Para compor o instrumento, tomamos como sugestão as duas últimas opçōes anteriormente apresentadas.

Quanto às figuras humanas utilizadas, optou-se por não apresentar desenhos, mas fotografias de pessoas reais projetadas em uma tela, sobre as quais versariam algumas perguntas do questionário. Como ensina FLICK (2004), o pesquisador pode mostrar fotografias (como demonstrador) para uma pessoa em estudo (como espectador), fazendo perguntas sobre o material.

Assim, o primeiro passo foi selecionar mulheres e homens dispostos a terem seus corpos medidos e identificados de acordo com as faixas da tabela do Índice de Massa Corporal, para, em seguida, serem fotografados. A dificuldade dessa etapa residiu na indisponibilidade dos homens de submeterem-se a esse processo, conduzindo a investigação na direção da análise da beleza do corpo feminino.

Não foi objetivo desse trabalho compreender as razões que levaram os homens a tal negação. Entretanto, reconhecendo o campo fértil para novos estudos, é importante tecer algumas análises acerca das identidades, das relaçôes sociais de gênero e desta masculinidade corporificada.

Para Sсотт (1995), gênero é entendido como um elemento constitutivo de relações sociais baseadas nas diferenças percebidas entre os sexos e como um modo inicial de dar significado às relações de poder. O "gênero" permitiu "identificar que os corpos, as gestualidades, as representações de saúde, beleza, performance e sexualidade são construçôes históricas que, em diferentes tempos e culturas foram associadas aos homens e/ou às mulheres, produzindo, ainda, representações de masculinidades e feminilidades" (Goellner, 2007, p.183). Sob este prisma, o fato das mulheres terem aceito e os homens terem negado se submeter à sessão de fotos ilustra a força daquilo que AUAD (2007) chama de conservas culturais, que perversamente distribuem os papéis sociais em normal e anormal, capaz e incapaz, eficiente e deficiente, "sexy" e assexuado, dominador e dominado. Essa dominação masculina pressupõe o que Bourdieu (2005) classifica como poder simbólico, pelos quais os dominados contribuem, muitas vezes à sua revelia ou até contra sua vontade, para sua própria dominação, aceitando os limites impostos e outras tantas maneiras de se submeter, ao juízo dominante.

Assim, cientes da finalidade do procedimento, sete mulheres, estudantes do curso de Licenciatura em Educação Física da Universidade de Pernambuco, dentro da faixa etária compreendida entre 18 e 22 anos, vestidas em trajes de banho, tiveram seus corpos medidos (massa e estatura) e fotografados de frente, de perfil e de costas. Tais fotografias foram utilizadas na confecção de um anexo sobre o qual contemplava várias perguntas do questionário. Convém salientar que, antes de serem manuseadas por terceiros alheios à pesquisa, tais imagens foram alteradas para que não houvesse identificação facial dos indivíduos, com o intuito de respeitar os aspectos éticos no tocante à pesquisa com seres humanos e de evitar exposição desnecessária e qualquer constrangimento para esses indivíduos. (Processo no 088/2005 do Comitê de Ética da Universidade de Pernambuco).

Foram elaborados dois tipos de questionários com perguntas fechadas, onde eram utilizadas escalas para avaliação da beleza, da satisfação pessoal com o próprio corpo, etc. Um dos questionários foi respondido por homens e outro por mulheres, sendo que o questionário destinado a elas era composto de questôes idênticas ao questionário dos homens, acrescido desta pergunta: Com qual destes corpos fotografados V. Sa. diria que o seu corpo mais se assemelha?

Para assegurar o grau de confiabilidade, o instrumento foi testado, criticado e refinado antes de ser aplicado à população objeto do estudo a fim de verificar a forma adequada o nível de aplicação (aplicabilidade) e de fidedignidade (reprodutibilidade e objetividade). O pré-teste foi realizado no Laboratório de Estudos em Práticas Esportivas e Lazer (LAPEL) da Escola Superior de Educação Física da Universidade de Pernambuco e, durante a préanálise do instrumento, foram detectados pontos de 
estrangulamento, que, prontamente, foram sanados, um deles foi a utilização de uma escala Likert com sete pontos ( 1 = "nada satisfeito" a 7 = "totalmente satisfeito"), para oferecer maior possibilidade de respostas e fazer com que os resultados expressassem com clareza o verdadeiro sentimento dos sujeitos.

\section{Procedimentos de coleta e análise de dados}

Durante o uso dos questionários foram observadas as seguintes etapas metodológicas: a) apresentação da proposta ao grupo onde seria aplicado o questionário. Neste momento foram esclarecidos o caráter voluntário da participação e a natureza confidencial das informações, antes da leitura e assinatura de termo de consentimento; b) a aplicação ocorreu nos períodos de aula nas instituições referidas; c) solicitação de disposição espacial e determinado comportamento individual dos integrantes das turmas, para que não houvesse interferência no preenchimento dos questionários; d) utilização de equipamento de projeção, para que as imagens fossem mostradas em maior tamanho e pudessem ser visualizadas por todo o grupo. Os sete conjuntos de fotografias referentes aos indivíduos foram projetados um de cada vez. Esse procedimento foi repetido e, em seguida, um vídeo contendo todas as fotografias foi projetado num primeiro momento individualmente, e depois permanecendo visível durante todo o processo de preenchimento dos questionários. Os dados foram analisados à luz da estatística descritiva com utilização do Programa SPSS versão 15.0.

\section{Resultados}

Analisando as imagens apresentadas, $(88,4 \%)$ dos sujeitos apontaram como mais belo o corpo equivalente à classificação magro no IMC. Em contrapartida, o corpo identificado como obeso foi taxado como menos belo por (89,9\%) dos sujeitos.

Sob a ótica de homens e mulheres, $(97,5 \%)$ daqueles e $(85,8 \%)$ destas afirmaram que o Indivíduo abaixo do peso era possuidor do corpo mais belo, enquanto o Individuo obeso foi classificado como o corpo menos belo por $(92,5 \%)$ deles e $(88,6 \%)$ delas.

Entre alunos e professores de Educação Física, (97\%) identificaram o Indivíduo abaixo do peso como detentor do corpo mais belo e os (3\%) restantes atribuíram esta qualidade ao Individuo Normal. Para profissionais de outras áreas, a classificação de corpo mais belo atingiu os seguintes índices: $(80,8 \%)$ para Indivíduo abaixo do peso; $(14,7 \%)$ para o Indivíduo normal e (4,5\%) para o Individuo obeso.

No quesito Auto-percepção e nível de satisfação pessoal com a própria imagem corporal, $(71,8 \%)$ dos homens estão satisfeitos; (15,4\%) nem satisfeitos, nem insatisfeitos; $(12,8 \%)$ estão insatisfeitos. Entre as mulheres, os índices são de $(51,1 \%) ;(27,6 \%)$ e $(21,3 \%)$, respectivamente.

A correlação entre gênero dos sujeitos e nível de satisfação com o próprio corpo em escala de 01 (nada satisfeito) a 07 (totalmente satisfeito) mostrou que os homens percebem a sua imagem corporal de maneira mais positiva que as mulheres. $(71,8 \%)$ deles colocaram-se em um dos três níveis mais altos de satisfação, enquanto que entre elas, este índice foi de $(51,1 \%)$ delas fizeram o mesmo. Vale ressaltar ainda que $(8,5 \%)$ das mulheres assinalaram um nível de insatisfação total com o próprio corpo.

Na correlação entre gênero dos sujeitos e simpatia à idéia de intervenção cirúrgica de caráter meramente estético, $(43,3 \%)$ das mulheres e $(24,4 \%)$ dos homens declararam que se submeteriam este tipo de cirurgia.

\section{Discussão}

O intuito agora é compreender o corpo feminino na sua linguagem, verificando os aspectos convergentes e divergentes nas análises apreendidas. Isso se tornará evidente a partir da discussão apresentada em relação ao corpo magro ter sido apontado como o mais belo, e o corpo gordo como o corpo menos belo, e ainda a partir do nível de satisfação com a imagem corporal, bem como a simpatia à ideia de intervenção cirúrgica na concepção de alunos, e de professores de educação física e outros profissionais, nesse início do século XXI. 


\section{O corpo mais belo}

Em resposta a uma pergunta simples e direta, qual o corpo mais belo, a maioria dos sujeitos identificou aquele que apresentou o índice que classifica os indivíduos como magro, como o corpo mais belo. Diante da margem percentual alcançada $(88,4 \%)$ é possível afirmar que os sujeitos responderam à questão baseados em um mesmo critério de classificação e julgamento, o que denota um padrão das respostas. E sabendo que esse indivíduo está inserido na faixa de IMC que o classifica como abaixo do peso, os números permitem atribuir caráter científico à afirmação comum que em nossa sociedade o corpo belo é o corpo magro. Valida essa colocação baixíssimo percentual de $(2,1 \%)$ atingido pelos corpos menos belos, ou seja, classificados nas faixas do IMC como Indivíduo obeso. É certo que magreza pode ser algo definido subjetivamente, mediante comparação de um indivíduo com outro de maior massa. Porém, mediante critérios científicos, só poderá ser conceituado como magro os corpos que cumpram tais parâmetros.

Essa configuração não era aquela apresentada nos séculos XIX nas pinturas da época, realçando que os períodos anteriores traziam também um padrão que retratava corpos volumosos e rotundos. Nessa época a gordura foi sinônimo de saúde, beleza e sedução (ANDRADE, 2003). Esta forma de se pensar a estética corporal chega a 1830, quando é inventado o código da beleza. Mais do que isso, confirma-se o ideal de beleza em voga desde o início da sociedade industrial e tendo sobretudo em conta o seu desenvolvimento acelerado na segunda metade do século XX, conforme indicadores apontados em diversos estudos (Conti, Petroli \& Gambardella, 2005; Maués, 2003; Teixeira, 2001; Wolf, 1992). LuPTON (2000) mostra que nesta época o corpo magro significava um testemunho do poder da autodisciplina, um exemplo do domínio da mente sobre o corpo e de um virtuoso sacrifício.

Nesse olhar, os achados encontrados no presente estudo sugerem que as mulheres e os homens preferem corpos mais magros, e rejeitaram o corpo mais volumoso. Esses resultados entretanto, contrariam os achados de DAMASCENO (2005), que estudou o tipo físico ideal e a insatisfação com a imagem corporal de um grupo de praticantes de caminhada.

\section{O corpo menos belo}

Foi perguntado no mesmo questionário qual dos corpos das pessoas fotografadas os sujeitos classificariam como o menos belo. Uma percentagem elevada
$(89,9 \%)$ recaiu no Individuo obeso. Fato inverso do que aconteceu ao Individuo portador do corpo magro. Uma percentagem pouco representativa $(2,9 \%)$ serve para comprovar a opção por esse padrão conforme foi evidenciado anteriormente.

Conforme dito anteriormente, o período da Revolução Industrial provocou mudanças em vários aspectos socioculturais, inclusive no campo da estética. Este momento histórico-social caracterizou-se pela proliferação das indústrias, pela otimização do tempo e dos espaços, pela produção desenfreada e ainda pela crescente necessidade de consumo de bens e serviços, passando a exigir corpos mais ágeis e aptos. Consequentemente, a gordura e o excesso de peso passaram a ser um obstáculo na visão de uma nova sociedade, configurando-se como um empecilho para os cidadãos que desejavam fazer parte dessa forma moderna e cosmopolita de viver que não combinava com o ócio e a imobilidade (AlmEIDA, 2002; BоTTI, 2003; Goldemberg, 2005a; Kateshita \& Almeida, 2006; NaTANSOHn, 2005). E no decorrer do século $\mathrm{XX}$, este olhar negativo sobre a obesidade passa a enxergá-la como um sinal palpável de falta de controle, impulsividade e auto-indulgência (LUPTON, 2000).

\section{O corpo mais e menos belo para homens e mulheres}

Os indivíduos - no masculino e no feminino, da infância à velhice, do nascimento até à morte - não vivem somente entre os objetos e os pensamentos do dia-a-dia; vivem com o seu corpo, por meio do seu corpo. Elemento de estudo da anatomia, da fisiologia, da biologia, entre outras ciências, o corpo transformou-se também em artefato da história. As representaçōes coletivas do corpo, esse habitáculo da saúde, da doença, do exercício físico, da sexualidade, são diferentes, conforme as sociedades e as épocas. Nesta dimensão, a história do corpo assume todo o seu significado ao nível do quotidiano (Le Goff, 1994 citado por Goellner, 2007).

Na busca por um significado do corpo, "[...] não se pode conceber mulheres, exceto se elas forem definidas em relação aos homens, nem homens, exceto se eles forem diferenciados das mulheres" (SCOTT, 1992, p.87 citado por Goellner, 2007, p.176). Diante deste entendimento, este estudo investigou se haveria diferença na maneira em que homens e mulheres percebem a beleza corporal feminina. Porém, não se pretendeu legitimar esta discussão com base exclusivamente no sexo biológico, mas sim averiguar a relação entre os gêneros masculino e feminino e a percepção de beleza corporal. 
O estudo apontou que homens e mulheres avaliaram de forma semelhante as imagens fotográficas que lhes foram apresentadas, evidenciando que indivíduos de ambos os gêneros perceberam igualmente a beleza no corpo feminino, apesar das diferenças sociais, históricas e políticas que os constroem masculinos e femininos.

A análise dos resultados mostrou que o Indivíduo abaixo do peso é classificado como possuidor do corpo mais belo pela maioria dos sujeitos, enquanto o Indivíduo obeso recebe classificação oposta, mas por percentual igualmente elevado. Os homens e as mulheres indicaram que o Indivíduo abaixo do peso foi classificado como possuidor do corpo mais belo com um índice de $(97,5 \%$ e $85,8 \%)$ respectivamente. E quanto ao corpo menos belo o percentual foi de $(92,5 \%$ e 88,6\%) respectivamente para o Indivíduo obeso.

Inseridos na mesma cultura, fruto do processo de acumulação de informações e representaçôes resultante de todo o passado histórico das geraçôes anteriores, homens e mulheres, ao mesmo tempo em que carregam consigo o que os fazem masculinos e femininos, são por vezes socialmente programados com base nos mesmos critérios. Por isso, avaliam igualmente como belo o corpo magro, ao mesmo tempo em que percebem como não-belo o corpo obeso.

Belo, bonito, beleza... Todas as palavras têm uma história; são diversos os símbolos, significados e interpretaçôes que reacaem sobre certos conceitos e relações. Ficar alheio a tal caráter social e historicamente elaborado pode se constituir num grande erro ao se trabalhar com o conceito de gênero, cujo ponto chave é fugir de explicações acerca das desigualdades fundamentadas nas diferenças físicas e biológicas, concentrando-se no seu caráter social, histórico e político (NichOLSON, 2000 citado por Vianna \& Unbenhaum, 2004; ScotT, 1995).

Gramaticalmente, o gênero é entendido como classificação; modo de expressão do sexo real ou imaginário dos seres; atribuição do masculino e do feminino. Entretanto, antes de figurar nos léxicos, o gênero foi usado pelas feministas como uma alusão à organização social da relação entre os sexos. Uma delas foi Joan ScotT (1995), que mais recentemente apropriou-se do conceito para destacar a linha fundamentalmente social das distinções baseadas no sexo, num esforço pela rejeição do caráter determinista da biologia, bem como para usar o gênero como uma categoria de análise capaz de gerar conhecimento histórico.

Convém frisar o uso do termo "gênero" como uma categoria analítica cujo foco aponta sobre a relação entre os sexos, mas enfatizando “(...) as conotações sociais do gênero em contraste com as conotações físicas do sexo" (SCOTT, 1992, p.81 citado por Vianna \& Unbenhaum, 2004). A explicação se faz necessária porque o termo "gênero" não é sempre entendido da mesma maneira.

Nicholson (2000) citado por Vianna e UnbeNHAUM (2004) afirma que a palavra gênero é utilizada de duas maneiras distintas e, até certo limite, contraditórias. Uma delas usa o "gênero" como oposição a "sexo" para diferenciar o que é biológico do que é construído socialmente, num entendimento comumente observado nas teorizações feministas iniciais. Em contrapartida, o outro olhar enxerga o "gênero" referindo-se às construçôes sociais relacionadas à distinção masculino/feminino, abarcando inclusive aquelas que isolam corpos femininos de corpos masculinos. Nota-se neste ponto a ideia "de que a sociedade forma não apenas a personalidade e o comportamento, mas também as maneiras como o corpo aparece" (p.9).

GoelLner (2007) diz que o gênero nos constitui, inscreve-se na nossa carne. Pode-se dizer também que "[...] os corpos na verdade carregam discursos como parte de seu próprio sangue" (BUTLER citado por Prins \& MEIJer, 2002, p.163). E os resultados apontaram que os "discursos" proferidos pelos corpos expostos nas fotografias utilizadas nesse estudo foram compreendidos da mesma maneira, tanto por indivíduos do gênero masculino quanto do feminino.

\section{O corpo mais belo para alunos e professores de educação física e outros profissionais}

Os resultados evidenciaram que os corpos não foram percebidos de forma diferente pelos sujeitos, sejam eles da área da Educação Física ou não. Percentuais elevados foram verificados em ambos os grupos no que toca à classificação do Indivíduo magro como possuidor do corpo mais belo.

$\mathrm{Na}$ primeira dimensão, os alunos e professores de Educação Física $(97,0 \%)$ apontaram o Indivíduo abaixo do peso como possuidor do corpo mais belo e (3,0\%) marcou o Indivíduo normal. Isto pode ter ocorrido devido ao fato dos profissionais e estudantes da área de Educação Física deterem um saber especializado acerca dos benefícios que o corpo magro pode trazer para a saúde. É possível que essa cultura restrita ao grupo acadêmico-profissional venha influenciar o contexto sociocultural onde ele se insere.

$\mathrm{Na}$ segunda dimensão, as respostas dos sujeitos de outras profissóes recaíram nos seguintes índices: (80,8\%) responderam o Individuo abaixo do peso; 
como o que detém o corpo mais belo; $(14,7 \%)$ indicaram o Individuo normal e (4,5\%) o Indivíduo obeso. Isto leva à concluir que, tanto o subgrupo formado por alunos e/ou profissionais de Educação Física, quanto o subgrupo composto por outros profissionais, possuem os mesmos critérios de julgamento e estão sob influência do(s) mesmo(s) fator(es) regulador(es).

\section{Auto percepção e satisfação pessoal}

Foi verificado que o total de homens insatisfeitos atinge (12,8\%), nem satisfeito nem insatisfeito $(15,4 \%)$, e satisfeito $(71,8 \%)$. Enquanto entre as mulheres, o indice de insatisfação foi de (21,3\%), nem satisfeita nem insatisfeita foi de $(27,6 \%)$ e a opção satisfeita chegou a (51,1\%). Cabe salientar que os achados (ANZAI, 2000; Cohen-Mansfield et al., 2004; Conti, Petroli \& GAMBARDELLA, 2005) apontaram nessa mesma direção. Entretanto os resultados da investigação (DAMASCENO, 2005) foram divergentes.

Se o indicador nem satisfeito nem insatisfeito for adicionado ao critério de análise de insatisfação, tais percentuais atingem $(28,2 \%)$ entre os sujeitos de gênero masculino e $(48,9 \%)$ entre os do gênero feminino. Ficou evidente também que a percepção dos homens em relação à sua imagem corporal é bem mais positiva do que a percepção das mulheres em relação à sua própria imagem. Os homens que se perceberam em um dos três níveis mais altos de satisfação somam $(71,8 \%)$ do grupo. Entre as mulheres, este número cai para $(51,1 \%)$, por pouco não cedendo o "status" de maioria para o percentual de mulheres insatisfeitas com o próprio corpo. Convém ainda destacar o sentimento de insatisfação total com o próprio corpo para $(8,5 \%)$ das mulheres.

\section{Simpatia à ideia de intervenção cirúrgica}

Dados da Sociedade Brasileira de Cirurgia PlástiCA divulgados em 2004 revelaram que no Brasil somente neste ano, foram realizadas $616.287 \mathrm{mil}$ cirurgias plásticas, sendo que $(69,0 \%)$ delas, ou seja, 425.288 foram realizadas em mulheres e $(31,0 \%)$ em homens, com 190.999 intervençōes. Dentre as intervençôes, 365.698 (59\%) do total foram de caráter estético, de tipos como: lipoaspiração, a mais realizada (54\%); mama em geral e implante (32\%); face em geral, atingindo (27,0\%). Vale ressaltar que no "ranking" nacional as regiōes Norte e Nordeste juntas realizaram 70.372 mil cirurgias plástica estética e reparadora. Esses dados se comparados, refletem uma predominância feminina no mundo dos pacientes de cirurgias plásticas de caráter estético.
No que diz respeito à questão da simpatia à ideia de intervenção cirúrgica por parte dos atores sociais, os resultados da investigação mostraram que são as mulheres os sujeitos mais simpáticos à ideia de submissão a processos cirúrgicos de caráter meramente estéticos. Dos entrevistados, $(43,3 \%)$ das mulheres admitiram que se submeteriam a tal tipo de cirurgia, contra $(24,4 \%)$ dos homens. Isto se deve ao fato de que a beleza, para a mulher, tornou-se imperativo absoluto (BAUDRILLARD, 1992).

Nesse sentido, cabe tecer considerações sobre o corpo enquanto instrumento tecnológico (GAYA, 2005; Goldemberg, 2005b; Silva, 1999; Swain, 2001; TeIXeIra, 2001) evocado pelo discurso sobre o transplante, no qual se trocam as peças, no apelo a uma eterna juventude, a um corpo produzido: $o$ modelo corporal está ao alcance de todas, na luta contra o tempo e as imperfeições. Esses indicadores, portanto, apontam uma situação convergente com os resultados advindos das variáveis relacionadas à auto percepção e satisfação pessoal anteriormente descritas, uma vez que mostrou as mulheres como sujeitos mais insatisfeitos em relação aos seus próprios corpos.

Ampliando a discussão para além dos tópicos trabalhados acima, podemos prosseguir analisando algumas categorias significativas para a interpretação e contextualização do corpo enquanto elemento da estética e do belo. Buscou-se isto pela crença de que não é possível analisar esse corpo sem o olhar multifacetado influenciado por categorias como o desporto, moda e mídia. Estes fenômenos de profundos rituais serão interpretados num cenário que favoreça sua natureza ritualística, dentro de uma lógica interna que determina a sua racionalidade e que consiste, como afirma BROHM (1976), na sua orientação para a procura da performance física.

Nessa dimensão, devemos levar em conta o estudo de SWAin (2001), que analisa, além do papel social definido em feminino e masculino, as representaçōes e imagens de gênero que constroem e moldam os corpos biológicos, moldando-os e sujeitando-os às práticas normativas que hoje se encontram disseminadas no Ocidente. Igualmente este autor afirma que uma vez construído o corpo, é preciso vesti-lo. Nesse caso a indústria da moda, assim como a cosmetologia e os perfumes, é o pilar das revistas femininas. E vai além quando diz que a moda seleciona os corpos aos quais se aplica, excluindo outros, ou então cria os corpos na moda, de acordo com o tipo ideal (ANDRADE, 2003; ANZAI, 2000; Botti, 2003; Freitas, 2005; KNiJNik \& Simôes, 2000; Maguire \& Mansfield, 1998). A 
tirania da moda não é uma palavra vã: os corpos se comprimem e se contorcem para se ajustar aos contornos da moda.

Ainda dentro da categoria analítica moda, os estudos desenvolvidos (Borges, 2005; Conti, Petroli \& Gambardella, 2005; Gaya, 2005; GoldemberG, 2005b; SWAIN, 2001; TeIXeIrA, 2001), mostram que a moda tem uma ligação direta com a divisão sexual e com a divisão em classes, mas nem por isso deixa de ser uma forma sutil de expressão de sentimentos pessoais. Sobretudo daqueles que se ressentem de falta de espaços socialmente legitimados para se expandirem. E nesse sentido, mostrando a complexidade de emoçôes e sentimentos que envolvem a moda, torna-se pertinente analisá-la como um fenômeno estético e sociológico. Pois ela é a mais viva de todas as artes, tal como a pintura, a escultura e a arquitetura; ela encontra na forma o seu veículo de expressão. $\mathrm{Ou}$ melhor, a moda é forma (SimMEL, 1988).

Indo um pouco mais além, uma outra pesquisa desenvolvida por GAYA (2005) analisou a despedida do corpo biológico. Nesse sentido, é legítimo tratar o corpo, mais do que uma obra biológica. Ele é uma construção cultural, social e histórica, erguido de diferentes formas, de acordo com o tempo e o lugar que ocupa. Assim, também instável e dinâmica é a forma como ele é representado socialmente.

Aprofundando mais essa análise, passa-se agora a discutir outra variável sociocultural, resultado de diversos estudos (Almeida, 2002; Almeida et al., 2005; Borges, 2005; Conti, Petroli \& GambarDELLA, 2005; FisCHER, 2001; GOLDEMBERG, 2005b; Kateshita \& Almeida, 2006; TeIXeIra, 2001) que será objeto de reflexão nesse momento. Trata da pressão da mídia do ponto de vista negativo, nas campanhas publicitárias em revistas de moda, comparando atributos e/ou atrativos com os dos modelos apresentados. Certamente essa distorção da imagem corporal encontra raízes nos meios de comunicação de massa que privilegiam modelos de beleza que possuem pesos para estatura próxima ou mesmo semelhante a portadores de distúrbios alimentares como anorexia nervosa e bulimia. Esses padrōes de beleza apresentados pela mídia exercem influência sobre o comportamento e hábitos alimentares saudáveis (FisCHER, 2001; GOLDEMBERG, 2005a; SwAIN, 2001).

\section{Conclusão}

Entre outras evidências foi possível inferir: a) existe na nossa sociedade um padrão de beleza corporal que define como belo o corpo que é classificado como abaixo do peso mediante o Índice de Massa Corporal; b) o corpo feminino classificado como belo por estudantes e profissionais do ramo da Educação Física é o mesmo definido como tal por sujeitos que não compõem este subgrupo social. Ambos os grupos apontaram o mesmo padrão de beleza corporal; c) indivíduos de ambos os gêneros perceberam igualmente a beleza no corpo feminino; d) as mulheres são mais insatisfeitas com sua imagem corporal do que os homens; e) como reflexo desta insatisfação, as mulheres são mais simpáticas à ideia de se submeterem a procedimentos cirúrgicos de caráter meramente estéticos.

Aproveitando a temática da insatisfação feminina com sua imagem corporal, seria importante salientar a correlação do estudo com a problemática dos graves distúrbios sócio-psicológicos relativos à autopercepção corporal, tais como a anorexia nervosa e a bulimia. Para ilustrar a gravidade do tema, as palavras de GARCiA (2008) são contundentes: a anorexia nervosa apresenta a maior taxa de mortalidade ao ano, dentro de todos os transtornos psiquiátricos no Brasil, ocorrendo geralmente nas mulheres. As causas destes óbitos vão desde inanição a suicídio por depressão. Assim, cabe um alerta para os aspectos nocivos e até fatais que podem vir agregados ao exagero na busca pelo corpo magro, numa das diversas formas que os conflitos relativos à auto-imagem podem assumir na sociedade atual.

Espera-se, com este trabalho, ter dado uma contribuição para que o ser humano, especialmente as mulheres, desperte em si o olhar crítico sobre sua a cultura na qual está inserido, seus valores e seu comportamento, podendo entender os elementos que a compõem e que, como a própria cultura, são passíveis de mudança. 


\begin{abstract}
The beauty standard over the female body based on the BMI

The objective of this study was to confirm the existence of a beauty standard over the feminine body and to define it by means of a scientific standard, which is the Body Mass Index, as well as to know how this body is socially represented. One hundred and fifty-one subjects, including undergraduate and postgraduate students of Physical Education from the State University of Pernambuco, answered a questionnaire that included questions which allowed the analysis of a panel containing photos of 7 women aged between 18 and 22 years. Not only the existence of a standard of physical beauty in our society was confirmed, but also a tendency to uniformity in the perception of a beautiful body by Physical Education students and professionals, as well as by individuals not included in this group.
\end{abstract}

UnITERMS: Aesthetics; Beauty; Body image; BMI.

\title{
Referências
}

AMERICAN COLLEGE OF SPORTS MEDICINE (ACSM). Diretrizes do ACSM para os testes de esforço e sua prescrição. 6. ed. Rio de Janeiro: Guanabara Koogan, 2003.

AFONSO, A.; FERNANDES, A.; GOMES, C.; SOARES, D.; FONSECA, A. Estudo exploratório sobre os motivos que levam as pessoas a praticar aeróbia. In: FONSECA, A. A FCDEF-UP e a psicologia do desporto: estudos sobre motivação. Porto: Faculdade de Ciências do Desporto e de Educação Física/UP, 2000.

ALMEIDA, G. A imagem corporal de mulheres morbidamente obesas avaliada através do desenho da figura humana. Psicologia: Reflexiva e Crítica, Porto Alegre, v.15, n.2, p.283-92, 2002.

ALMEIDA, G.; SANTOS, J.; PASIAN, S.; LOUREIRO, S. Percepção de tamanho e forma corporal de mulheres: estudo exploratório. Psicologia em Estudo, Maringá, v.10, n.1, p.27-35, 2005.

ANDRADE, S. Saúde e beleza do corpo feminino: algumas representações no Brasil do éculo XX. Movimento, Porto Alegre, v.9, n.1, p.119-43, 2003.

ANZAI, K. O corpo enquanto objeto de consumo. Revista Brasileira de Ciência do Esporte, Campinas, v.21, n.2-3, p.71-6, 2000. AUAD, J. Inserção social universitária: uma leitura psicodramática. 2007. 147 f. Dissertação (Mestrado em Psicologia Clínica e Cultura) - Universidade de Brasília, Brasília, 2007.

BARROS, D. Imagem corporal: a descoberta de si mesmo. História da Ciência e Saúde: Manguinhos, Rio de Janeiro, v.12, n.2, p.547-54. 2005.

BAUDRILLARD, J. A sociedade de consumo. Lisboa: Edições 70, 2005.

Da sedução. 2. ed. Campinas: Papirus, 1992.

BELLONI, M. O lazer espetacularizado: cultura do narcisismo e indústria cultural. Motrivivência, São Cristovão, v.12, n.17, p.85-103, 2000.

BÉRGAMO, A. Elegância e atitude: diferenças sociais e de gênero no mundo da moda. Caderno Pagu, Campinas, n.22, p.83-113. 2004. BORGES, M. Gênero e desejo: a inteligência estraga a mulher? Revista de Estudos Feministas, Florianópolis, v.13, n.3, p.667-76, 2005.

BOTTI, M. Fotografia e fetiche: um olhar sobre a imagem da mulher. Caderno Pagu, Campinas, n.21, p.103-31, 2003.

BOURDIEU, P. A dominação masculina. Rio de Janeiro: Bertrand Brasil, 2005.

BROHM, J. Sociologie politique du sport. Paris: J.P. Delarge, 1976.

CASTRO, M.; ANDRADE, T.; MULLER, M. Conceito mente e corpo através da história. Estudos Psicológicos, Maringá, v.11, n.1, p.39-43. 2006.

COHEN-MANSFIELD, J.; MARX, M.S.; BIDDISON, J.R.; GURALNIK, J.M. Socio-environmental exercise preferences among older adults. Preventive Medicine, New York, v.38, n.6, p.804-11, 2004.

CONTI, M.; PETROLI, M.; GAMBARDELLA, A. Excesso de peso e insatisfação corporal em adolescentes. Revista de Nutrição, Campinas, v.18, n.4, p.491-7, 2005.

COSTA, A. Dos símbolos e mitos desportivos a estética do humano. Desporto, Investigação \& Ciência, Porto, n.0, p.49-58, 2002. 
DAMASCENO, V. Tipo físico ideal e satisfação com a imagem corporal de praticantes de caminhada. Revista Brasileira Medicina do Esporte, São Paulo, v.11, n.3, p.181-6, 2005.

DEMO, P. Metodologia do conhecimento científico. São Paulo: Atlas, 2000.

ECO, U. (Org.). História da beleza. Tradução de Eliana Aguiar. Rio de Janeiro: Record, 2004.

FERREIRA, A. Novo Aurélio século XXI: O dicionário da língua portuguesa. Rio de Janeiro: Nova Fronteira, 2000.

FERREIRA, M.; FEIJÓ, O. Mulheres na meia-idade e corporeidade. Motus Corporis, Rio de Janeiro, v.6, n.1, p.101-27, 1999.

FISCHER, R. Mídia e educação da mulher: uma discussão teórica sobre modos de enunciar o feminino na TV. Revista de

Estudos Feministas, Florianópolis, v.9, n.2, p.586-99, 2001.

FLICK, U. Uma introdução à pesquisa qualitativa. 2.ed. Porto Alegre: Bookman, 2004.

FOUCAULT, M. Microfísica do poder. 17.ed. Rio de Janeiro: Edições Graal, 1979.

FREITAS, C. Da emoção a contradição no esporte: uma reengenharia da modernidade. Recife: EDUPE, 2005.

FREITAS, C.; SANTIAGO, M. Aspectos motivacionais que influenciam a adesão e manutenção de idosos a programas de exercícios físicos. Revista Brasileira de Cineantropometria e Desempenho Humano, Florianópolis, v.9, n.1, p.92-100, 2007. FURLAN, R.; BOCCHI, J. O corpo como expressão e linguagem em Merleau-Ponty. Estudos Psicológicos, Natal, v.8, n.3, p.445-50. 2003.

GARCIA, F. Anorexia nervosa: um transtorno psicológico. Disponível em: <http://www.endocrino.org.br/conteudo/publiCo_exibe.phpid.Not=65>. Acesso em: 29 fev. 2008.

GARCIA, R.; LEMOS, K. A estética como um valor na Educação Física. Revista Paulista de Educação Física, São Paulo, v.17, n.1, p.32-40, 2003.

GAYA, A. Será o corpo humano obsoleto? Sociologias, Porto Alegre, n.13, p.324-37, 2005.

GOELLNER, S. Feminismos, mulheres e esportes: questōes epistemológicas sobre o fazer historiográfico. Movimento, Porto Alegre, v.13, n.2, p.171-96, 2007.

GOLDEMBERG, M. Dominação masculina e saúde: usos do corpo em jovens das camadas médias urbanas. Ciência \& Saúde Coletiva, Rio de Janeiro, v.10, n.1, p.91-6, 2005a.

Gênero e corpo na cultura brasileira. Psicologia Clínica, Rio de Janeiro, n.2, p.65-80, 2005 b.

INSTITUTO BRASILEIRO DE GEOGRAFIA E ESTATÍSTICA (IBGE). Índice de massa corpórea: calcule seu IMC.

2002. Disponível em: <http://www.ibge.gov.br/home/estatistica/populacao/condicaodevida/pof/2002/imc_calculo.php>. Acesso em: 8 out. 2008.

Pesquisa de orçamentos familiares 2002-2003: antropometria e análise do estado nutricional de crianças e adolescentes no Brasil. 2003. Disponível em: <http:/www.ibge.gov.br/home/estatistica/populacao/condicaodevida/pof/2003medidas/ comentario.pdf>. Acesso em: 4 jun. 2007.

KANT, I. Observaciones acerca del sentimiento de lo bello e de lo sublime. Tradução de Luís Jiménez Moreno. Madrid: Alianza Editorial, 1990.

KATESHITA, I.; ALMEIDA, S. Relação entre índice de massa corporal e a percepção da auto-imagem em universitários. Revista de Saúde Pública, São Paulo, v.40, n.3, p.497-504, 2006.

KLAFS, C.; LYON, M. A mulher atleta: guia de condicionamento e treinamento físico. 2.ed. Tradução de Nelson Gomes Bittencourt, Berenice Salazar Figueira, Giuseppe Taranto. Rio de Janeiro: Interamericana, 1981.

KNIJNIK, J.; SIMÕES, A. Ser é ser percebido: uma radiografia da imagem corporal das atletas de handebol de alto nível no Brasil. Revista Paulista de Educação Física, São Paulo, v.14, n.2, p.196-213, 2000.

LACERDA, Y. Estética, desporto e atividade corporal suave. Motus Corporis, Rio de Janeiro, v.5, n.1, p.57-70, 1998.

LIPOVETSKY, G. O império do efêmero: a moda e o seu destino nas sociedades modernas. Lisboa: Publicaçóes Dom Quixote, 1989. LUPTON, D. Corpos, prazeres e práticas do eu. Educação e Realidade, Porto Alegre, v.25, n.2, p.15-48, 2000.

MAGUIRE, J.; MANSFIELD, L. "No-body's perfect": women, aerobics and the body beautiful. Sociology of Sports Journal, Champaign, v.15, n.2, p.109-37, 1998.

MATA, V. Da força física à estética corporal: as mudanças nas relações sociais retratadas no corpo. Revista da Educação Física UEM, Maringá, v.9, n.1, p.35-43, 1998.

MAUÉS, R. 'Bailando com o Senhor": técnicas corporais de culto e louvor (o êxtase e o transe como técnicas corporais). Revista de Antropologia, São Paulo, v.46, n.1, p.10-40. 2003

MINAYO, M. O desafio do conhecimento: pesquisa qualitativa em saúde. 2 ed. São Paulo: Hucitec, 2006.

MRAZEK, J.; FIALOVÁ, L.; BYKHOVSKAYA, I. Sport, health and body concepts in Central and Eastern Europe: students of physical education in Cologne, Prague and Moscow. Journal of Comparative Physical Education and Sport, v.20, n. 2, p. 53-64, 1998.

Rev. bras. Educ. Fís. Esporte, São Paulo, v.24, n.3, p.389-404, jul./set. 2010 • 403 
FREITAS, C.M.S.M. et al.

NATANSOHN, L. O corpo feminino como objeto médico e “mediático”. Revista Estudos Feministas, Florianópolis, v.13, n.2, p.287-304, 2005.

NOVAES, J. A ginástica de academia brasileira analisada segundo os postulados da estética de Schiller, Vieira de Mello e Maffesoli. Motus Corporis, Rio de Janeiro, v.6, n.1, p.38-60, 1999.

PONTES, H. A paixão pelas formas. Novos Estudos: CEBRAP, São Paulo, n.74, p.87-105, 2006.

PRINS, B.; MEIJER, I.C. Como os corpos se tornam matéria: entrevista com Judith Butler. Revista Estudos Feministas, Florianópolis, v.10, n.1, p.155-67, 2002.

SCOTT, J. Gênero: uma categoria útil de análise histórica. Recife: SOS Corpo, 1995.

SILVA, P. O lugar do corpo: elementos para uma cartografia fractal. Lisboa: Instituto Piaget, 1999.

SIMMEL, G. Filosofia do amor. São Paulo: Martins Fontes, 1988.

SOARES, A. Velhos esportistas: utilidade e estética. Motus Corporis, Rio de Janeiro, v.4, n.2, p.102-120, 1997.

SOCIEDADE BRASILEIRA DE CIRURGIA PLÁSTICA. Número de cirurgias plásticas não registra aumento em 2004.

2004. Disponível em: <http://www.cirurgiaplastica.org.br/publico/novidades02.cfm>. Acesso em: 4 out. 2006.

SUASSUNA, A. Iniciação à estética. 7.ed. Rio de Janeiro: José Olympio, 2005.

SWAIN, T. Feminismo e recortes do tempo presente: mulheres em revistas "femininas". São Paulo Perspectiva, São Paulo, v.15, n.3, p.67-81, 2001.

TEIXEIRA, S. Produção e consumo social da beleza. Horizontes Antropológicos, Porto Alegre, v.7, n.16, p.189-220, 2001.

THOMAS, J; NELSON, J. Métodos de pesquisa em atividade física. 3ed. Porto Alegre: Artmed, 2002

UVINHA, R. O corpo-imagem jovem e o fenômeno do consumo. Movimento, Porto Alegre, v.3, n.4, p.49-51, 1996.

VANNUCHI, C. Bonita, eu? Isto É, Rio de Janeiro, n.1826, p.68, 2004.

VIANNA, C.; UNBEHAUM, S. O gênero nas políticas públicas de educação no Brasil: 1988-2002. Cadernos de Pesquisa, São Paulo, v.34, n.121, p.77-104, 2004

WOLF, N. O mito da beleza: como as imagens de beleza são usadas contra as mulheres. Tradução de Waldéa Barcellos. Rio de Janeiro: Rocco, 1992.

WORLD HEALTH ORGANIZATION (WHO - Europe). Body mass index (BMI). Disponível em: <http://www.euro. who.int/nutrition/20030507_1>. Acesso em: 8 out. 2008.

\section{Agradecimentos}

Os autores agradecem o apoio recebido através da Bolsa do Programa Institucional de Iniciação Científica da Universidade de Pernambuco (FDPE/UPE).

Clara Maria Silvestre Monteiro de Freitas

R. Amazonas, 223, apto. 802 51011-020 - Recife - PE - BRASIL e-mail: clarasilvestre@uol.com.br

Recebido para publicação: 27/11/2008

Revisado em: 16/06/2009

Aceito: 06/05/2010 